\title{
İş Akış Motoru Tasarımı ve Gerçekleştirilmesi
}

\section{Workflow Engine Design and Implementation}

\author{
Oğuzhan Kayış ${ }^{*}(\mathbb{0}$, Semih Utku 1 (1) \\ ${ }^{1}$ Dokuz Eylül Üniversitesi Mühendislik Fakültesi Bilgisayar Mühendisliği Bölümü, İzmir, TÜRKiYE \\ Sorumlu Yazar / Corresponding Author*: oguzhan.kayis@ceng.deu.edu.tr
}

Öz

Bu çalışma özellikle büyük ölçekli işletmelerin süreçlerinde kullandıkları bir yapı olan iş akışı motorunun dinamik işleyecek şekilde bir tasarımını ve gerçekleştirilmesini kapsamaktadır. Üzerinde çalıştığımız temel konu, geliştirdiğimiz sistemin farklı işletmelere ve işletmeler içerisindeki farklı süreçlere uyum sağlayabilecek esneklikte olmasıdır. Endüsriyel alanlarda iş süreci bir çok etmene göre zamanla değişmektedir. Bu amaçla çalışma kapsamında iş akış motoruyla bütünleșik çalışabilen bir kural motoru geliştirilmiştir. Kural motoru, iş akış motorunun değișen iş süreçlerine çalışma zamanlı olarak uyum sağlamasını amaçlamaktadır. Tasarlanan bu sistem, bir teknoloji ürünleri firmasında, ürünlere bağlı belgelerin takip süreçlerini otomatize etmek üzere uygulanmıştır. Uygulama sonucunda toplanan bilgiler, sıralı örüntü madenciliği yöntemleri kullanılarak analiz edilmiștir.

Anahtar Kelimeler: İ̧̧ Akış̧ Motoru, Kural Motoru, Sıralı Örüntü Madenciliği, Belge Takip Sistemi

\begin{abstract}
This study includes a design and implementation of a workflow engine which is a structure that is used in the processes dynamically of the large-scale enterprises. The main issue is creating a dynamic system that is flexible enough to adapt to different businesses and different processes within the enterprises. Business process in industrial areas changes over time according to many factors. For this purpose, within the scope of the study, a rule engine integrated with the workflow engine was developed. The rule engine enables the workflow engine to adapt to changing business processes at runtime. This system was designed to automate the follow-up processes of the documents connected to the products in a technology products company. In addition, the results of the study were analysed using sequential pattern mining methods.
\end{abstract}

Keywords: Workflow Engine, Rule Engine, Sequential pattern mining, Document Tracking System 


\section{Giriș}

20.yy'ın sonlarına doğru firmalar, bünyelerine bașka firmaları almaya veya çeșitli alt birimlere bölünmeye başladılar. Farklı birimlerden oluşan firmalar grubu, kendi içlerindeki işlerde de satış, lojistik ve dağıtım, pazarlama, üretim, finans gibi alt modüllere ayrıldılar. Büyüyen firmaların alt bölümleri arasındaki iletişim ve sistematik gereksinimi bilgi teknolojileri birimlerinin oluşmasını ve ERP çözümlerini gerektirdi [1]. Gelişen firmaların bünyesinde kurulan bilgi ve teknoloji birimleri yazılım temelli iletişim çözümleri üretmektedir. Elektronik posta alt yapısı ile beslenen bu çözümler farklı iș akıș süreçlerini üretmiș ve bu süreçlerin yönetilebilmesi için de bu modüllerle bütünleşmiş çalışabilen iş akış motorları geliştirilmiştir.

İş akışı motoru, endüstriyel anlamda iş süreçlerini yöneten içerisinde yazılım ve insan kaynakları barındıran bir sistemdir [2]. Firmalar iș akıș motorlarını, özellikle satıș \& dağıtım ve muhasebe bölümlerince sürece dahil olan satış siparişi, satın alma siparişi, fatura, irsaliye gibi belgelerin takibinde kullansalar da üretim sahasında da ürün ile ilgili bilgilerin birimler arasında paylaşımı amacıyla da kullanmaktadırlar.

Endüstriyel anlamda iş genellikle birden fazla aktiviteden oluşmaktadır. Her bir aktivite belirli bir işlem birimi tarafından gerçekleștirilir. $\mathrm{Bu}$ birmlere örnek olarak çalışan gruplar, yazılım ya da veri tabanı yönetim sistemleri verilebilir [3]. İş akışı sistemleri de iki farklı grup altında toplanmaktadır. Bunlardan ilki faaliyet tabanlı olan iş akışı yönetim modelidir. Bu modelde ișin tamamlanması için gereken faaliyetlere odaklanılır. Diğer bir tür ise obje (varlık) tabanlı uygulamadır. Bu modelde ise ilkinin aksine işin tamamlanması için objenin mümkün olan hareketleri tanımlanır [4]. Bu çalışma obje tanımlı bir iş akıșı motoru geliștirilmek üzere tasarlanmıştır.

$\mathrm{Bu}$ çalıșma kapsamında iş akıșı motoru modellemesi aşamasında sonlu durum makineleri yapısı kullanılmıştır. Bu çalışma bir sonlu durum makinesinin ilişkisel bir veri tabanında nasıl saklanabileceği sorusuna da cevap vermektedir. Ayrıca çalışma kapsamında iş akışı motorunu esneklik yönüyle güçlendiren bir kural motoru da tasarlanmış ve gerçekleștirilmiştir.
Kural motoru doğrudan yazılımcı olmayan bireylerin, iş süreci yönetim sistemindeki akışa müdahale edebilmesine olanak sağlayan bir yazılım bileşenidir. Son yıllarda kolay okunabilir ve bakım yapılabilir bir yöntem olduğundan oldukça popüler bir hale gelmiștir $[5,6]$. İş kuralı bir akışı ve prosedürünü belirlemeye yarayan ifadedir. Geliștirilen kural motoru ile temel bir yazılım diline benzer şekilde kullanıcı ifadeleri karşılaştıracağı, sonucu doğru ya da yanlış olabilen denklemler kurabilir. Bu denklemlerin sonucuna göre atamalar yapabilir.

Tasarlanan bu çözüm bir teknoloji üretim firmasında ürünlerle ilgili belgelerin takibi süreçlerini sanallaştırmak amacıyla gerçekleştirilmiştir. Firmanın dış ticaret bölümünün gerçekleștirdiği belge talebi ile başlayan süreç, talebi oluşturulan belgenin önceden sinıflandırılan birimlere iletilmesi, belgelerin onay, ret, hazırlık ve talep sahibine geri bildirim adımlarını kapsayacak şekilde uygulanmıştır. $\mathrm{Bu}$ sistemden kurulmasından önce, firmada manuel olarak yönetilen bu süreç, bu çalışmayla birlikte otomatize edilmiştir. Geliştirilen sistemin içerisinde kullanıcı işlem bazlı veriler loglanmıştır. Projenin canlı sürece geçmesiyle birlikte ilk altı ayın sonucunda, girilen belge taleplerinden elde edilen veri üzerinde, sıralı örüntü madenciliği teknikleri uygulanmıştır. Alınan sonuçlar ilgili iş birimleri ile paylaşılmış ve talep edilen bazı belgelerin bir paket halinde talep edilmesi önerilmiștir.

\section{1. İlişkili çalışmalar}

Literatürde, yapılan çalıșmaları iş akış ve kural motoru üzerinden iki farklı şekilde işlendiği görülmüștür. $\mathrm{Bu}$ sistemler genellikle birbirinden bağımsız olarak geliştirilmiş olsalar da özellikle gelișen ERP (Entireprice Resource Planning) sistemleri ile bu iki ürünün bütünleşik yapıda kullanıldığı durumlar da bulunmaktadır.

Bir grup bilim adamının 1995 yılında yayınladıkları bir makalesinde gelișen endüstriyel hayatın bir doğal sonucu ve gerekliliği olarak, iş akışı yönetim süreçlerini ele almıştır. Çalışmada iş akışının modellenmesinden uygulanmasına kadar olan süreçteki farklı yaklaşımlar sınıflandırılmış ve iş akışı yönetiminde kullanılan terimler açılklamıştır [7]. 
Wil van der ve Aalst Kees van Hee, 2000 yılında yayımladıkları kitapta iş akışı süreçleri, yönetimi ve bu sürecin bilgi teknolojileri ile ilişkisini derinlemesine incelemişlerdir. $\mathrm{Bu}$ çalışmada sunulan modelde petrinetler üzerinden bir modelleme tarif edilmektedir. Kitapta yapılan çalışmanın uygulanabileceği alanlar bir seyahat acentesi, bisiklet fabrikası, sürüș okulu gibi farklı endüstri kolları üzerinde örneklendirilmiştir. Çalışmada iş akışının işletmenin verimini artırabilmesi için sürdürülebilir ve okunabilir bir yapıda tasarlanması gerektiği vurgulanmaktadır [8].

Chun Ouyang ve diğerlerinin 2010 yılında yayımladıkları bir diğer çalıșmada, daha eski bir çalışmaya atıfta bulunarak petrinetlerin bir alt kümesi olarak WF-net'lerden bahsettikten sonra YAWL isimli projeyi farklı başlıklar altında incelemişlerdir. Bir iş akış motorunun süreci nasıl tanımlayabileceği gibi genel kavramlardan da bahsedilen bu çalışmada, bizim çalışmamıza benzer olarak ayrıca veri madenciliği üzerinde de durulmuștur. Hem sistem hem de işlem loglarının anlamlı bir veri içerebileceğinden ve bu veri üzerinde yapılacak bir çalışmanın faydalı olabileceğinden bahsedilmiştir [2].

Bouafia ve Molnár 2018 yılında yayınladıkları çalışmalarında iş akışı modellemesi için kullanılan yapıları statik ve dinamik olarak ikiye ayırmıștır. Makalede günlük hayatta endüstrinin ihtiyaçlarının dinamik olarak değiştiği ancak sıklıkla kullanılan iş akışı motorlarının statik yapıda olduğu vurgulanmış ve dinamik iş akışı motoru için öneride bulunulmuştur. Ayrıca bu çalışmada iş akış motoru başlığı altında ayrıca açıkladığımız temel desenler de açlklanmıştır [9].

İş akış motorlarının evriminin anlatıldığı Krasimira ve diğerlerinin yapmış olduğu çalışmada; iş akış motorlarının evrimsel gelişimi başlığı altında hem tarihsel süreç incelenmiş hem de iş akış motorları üç farklı şekliyle sınıflandırılmıștır. Bu bașlıklar; ticari ve bilimsel anlamda yazılımlar, yazılım diline göre araçlar, destekledikleri standartlara göre araçlar şeklinde sınıflanmıştır[10].

Çalışmalar kapsamında Erwin ve Jacops'ın bir kural motoru da geliștirildiği görülmektedir. Erwin ve Jacops'ın geliştirdikleri Java tabanlı kural motoru ile ilgili makalelerinde, kural motorunun birçok alanda kullanabilecek bir yazılım olmasına karșın yaygın olarak kullanmadığı vurgulanmıștır [11]. Geliștirilen çözümün herhangi bir Java uygulaması ile bütünleşmiş çalışabildiğinden bahseden yazarlar ayrica kural motorunun bir bildirim aracı olarak da değerlendirilebileceğinin üzerinde durmuşlardır.

Rakesh ve diğerlerinin yaptığı çalışmada graph modeli üzerinden incelenen örnek iş akışı șemalarının logları üzerinde durulmuştur. Hem gerçek hem de örneklemeler üzerinden oluşturulan sentetik veriler üzerinden, çeşitli analizler yapılarak bir iş akışının başlangıç ve bitiş noktaları sıralanmış ve veri kümeleri oluşturulmuştur. Oluşturulan veri kümeleri üzerinden graph modeli üzerindeki en kısa yol bulunması ya da gürültü (noise) verinin belirlenmesi çalışmaları uygulanmıştır [12].

İş akış motoru uygulamaları ile veri madenciliği yöntemlerinin kullanıldığı bir diğer uygulamada da ilk olarak 2003 yılında Aalst ve diğerleri tarafından yayınlanmıștır. Çalıșmada iș akıșı motorları üzerindeki veri madenciliğinin başlangıç noktası, log olarak tanımlanmıştır. İşlemsel (transactional) log verileri üzerinden anlamlı verinin nasıl çıkrılabileceğinin örnekleri verilen bu çalıșmada ayrıca ERP, CRM (Customer Relationship Management) uygulamalarında da benzer şekilde işlemsel log verisi üzerinden örnekler verilmiştir [13].

Singh ve Sandeep'in 2011 yılında yayınladıkları bir çalışmada yine iş akışı motorlarını üzerinden veri madenciliği yöntemleri üzerinde durulmuștur. Ancak diğer çalıșmalarda loglardan anlamlı veri çıkarmak üzere iken bu çalışmada amaç; eylemleri inceleyerek petrinetler ile yeni bir model tasarlanmasıdır [14]. İș akışı yönetim sistemlerinde modelin belirlenmesi, iş ekibi açısından yüksek bir sorumluluk ve zaman gerektirdiğinden bu ișlem için veri madenciliği kullanılması önerilmiştir.

Bu çalışma özünde bir iş akış motoru tasarımı ve gerçekleștirilmesine içerse de arka planda bu iş akış motoruna esneklik kazandıracak ek bir kural motoru tasarımı sunmaktadır. Ayrıca yapılan çalışmanın örnek belge takip sistemi gerçekleştirmesinden elde edilen bilgiler ile veri madenciliği yöntemleriyle analizler yapılmıştır. $\mathrm{Bu}$ yönüyle sıralı örüntü madenciliğinin bir iş akışı motoru üzerinde nasıl uygulanabileceği de bu çalışma kapsamında gerçekleștirilmiștir. 


\section{Materyal ve Metot}

\section{1. İș akıș motoru genel özellikleri}

Yapılan bir başka çalışma kapsamında gerçekleştirilen iş akış motoru endüstriyel anlamda bir iş sürecinin tamamının ya da bir bölümünün otomatize edilmesi kurallarını kapsamaktadır [15]. Bu kurallar bir sonlu durum makinesi yapısına benzerlik gösterdiğinden çalışma kapsamında bir sonlu durum makinesinin ilișkisel bir veri tabanında nasıl modellenebileceğinin de üzerinde durulmuștur.

Temel bir akış içerisinde aşağıdaki yapılar bulunmaktadır [4];

- Durumlar: takibi yaplacak objenin bir $t$ anında bulunması mümkün olan her yapı bir durum olarak tanımlanır. Başlangıç, bitiş, iptal gibi özel durumların yanı sıra sayısız olarak uygulanan proje bazlı özelleşmiş durumlar olabilir.
- İşlemler: bir durumdan diğerine geçilmesi işlemidir. İş yapısı gereği genellikle tüm durumlar arasında bir bağ bulunmak zorunlu değildir. Başlangıç durumundan bir diğer duruma ve bu şekilde son duruma kadar olan tüm geçişler birer işlem olarak adlandırılır.

- Eylemler: işlemin gerçekleştirilebilmesi için gereken işleme eylem adı verilir. Bir iș akış motorunda eylemler mutlaka önceden belirlenmeli ve hangi eylemle hangi işlemin tamamlanacağına karar verilmelidir.

- Yetkiler: durumlar arasında geçişin anlatıldığı işlemler eylemler ile tetiklenir. Bu eylemlerin tetiklenmesi iş sürecinin güvenliği ve birbirinden farklı işlerin sahiplerinin ayrımı için gereklidir.

Şekil 1'de iş akış motorunu uyguladığımız belge takip sistemine ait bir belgenin akış diyagramı gösterilmektedir.

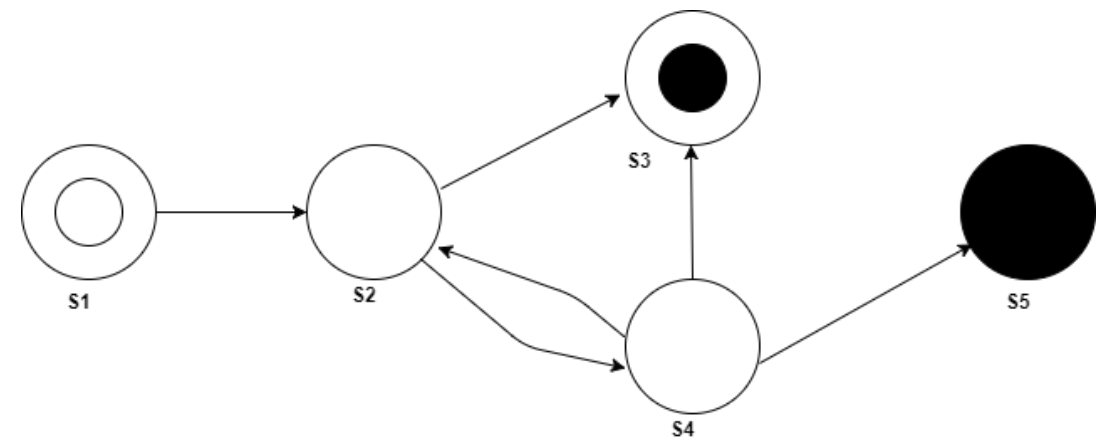

Şekil 1. Örnek bir akış diyagramı

Şekil 1'de gösterilen iş akış diyagramında S1, S2, S3, S4, S5 durumları temsil etmektedir. Örnek iş akış diyagramındaki verilen durumlar kategorilere ayrılmıştır.

- S1: Başlangıç durumu

- S2, S4: Geçiş durumu

- S3: İptal durumu

- S4: Bitiş durumu.

Takip edilen obje bir $t$ anında bu yukarıdaki durumların herhangi birinde bulunabilir. Örnek gerçekleştirdiğimiz akıșta kararlı sonlu durum makineleri ile modelleme yapıldığından bir nesne bir $t$ anında sadece bir durumda bulunabilir [16].
Durumlar arasında gösterilen oklar işlemleri temsil etmektedir. Sistemde her bir işlem için bir ID tanımlanmıştır. Bu ID’ler işlemler için geçerli yetkilerin olușturulması için kullanılacaktır. Arka planda tekrarsız olarak bir anahtarla belirlenen işlemler de belge takibi özelinde kategorilere ayrılmıștır. Ön yüzde belirlenen butonlar tetiklendiğinde ilgili tipteki işlem tetiklenmektedir.

- S1-S2: İstek yaratılması

- S2-S4, S4-S2: Sonraki/önceki adıma geçiş/onay

- S2-S3, S4-S3: İptal durumuna geçiş

- S4-S5: Doküman eklenmesi, final durumuna geçiş. 
$\mathrm{Bu}$ ișlemlerin gerçekleşmesi için gereken aksiyon eylemleri göstermektedir. Geliştirilen yapıda eylemler de ön yüzde tetiklenebilmesi için sınıflandırılmıştır. Aşağıda, durumlar arasındaki geçiş için tanımlanan aksiyon tipleri listelenmiştir. Bu aksiyon tipleri, iş akışında bir grup için tanımlanabileceği gibi ayrı ayrı gruplara da tanımlanabilir.

- İstek açma aksiyonu

- Sonraki adıma geçiş aksiyonu

- İsteği geri çekme aksiyonu

- İstek için belge eklenmesi, isteğin sonlandırılması aksiyonu.

Nihayetinde bu eylemler için gereken kontroller de yetki yapısını olușturmaktadır. Geliștirilen sistemde yetki aksiyon ve yetkili grup beraberinde kullanılmıștır.

Klasik bir sonlu durum makinesini bir matris yapısında tutmak mümkündür [17]. Ancak eylemler durumlar ve işlemleri içeren bir yapı için tekrarsız ID'ler gerektiğinden ilişkisel bir veri tabanı olușturulmuștur. Așağıdaki Șekil-2 deki database diyagramda (ER Diagram) "_" işareti ile başlayan tablolar iş akış motorunun örnek gerçekleștirmesi olan belge takip sisteminin objeleri için olup, diğer tablolar genel yapıya aittir.

Şekil 2'de gösterilen tabloların içerikleri aşağıda açıklanmıștır.

State_TP: Durum tiplerini temsil eder, durumları içeren tablo ile ilişkilidir

States: Durumları temsil eder. Durum tiplerinin akıș özelinde tekrarlanması amacıyla oluşturulmuştur.

Action_TP: Eylem tiplerini temsil eder, eylemleri içeren tablo ile ilişkilidir.

Actions: Eylemleri temsil eder. Eylem tiplerinin akış özelinde tekrarlanması amacıyla oluşturulmuştur.

_Doc_TP: Doküman takip sistemi içerisindeki her bir tekrarsız akıș, belge tipi anahtar olarak belirlenmiștir.

Process: Doküman takip sistemindeki her bir akışı temsil eder. Her bir akış bu sistem özelinde talep edilecek malzemenin tipi ve belgenin tipi ile özelleştirilmiştir.
Transaction: Bir akıș içerisindeki tüm adımları göstermektedir. Burada bir durumdan geçilebilecek diğer durum da gösterilmektedir. Her bir durum için ayrı bir ID gösterildiğinden bir durumdan birden fazla duruma geçiş de tanımlanabilir.

User_Group: Sistem kullanıcl adı ile birimlerin eşlenmesi için kullanılmıştır.

Groups: Yetkilerde kullanılmak üzere birimlerin tanımlandığı tablodur.

Transaction_Action_Auth: Her bir işlem için hangi eylemin geçerli olduğunu ve bu eylem için hangi grubun yetkili olduğu tanımlamak için kullanılmıștır.

Request: Her bir işlem (Process) için gerçekleştirilebilecek bir istek objesini temsil eder.

_Request_Data: Belge takibi ișlemi için oluşturulan her bir isteği temsil eder. Bu tabloda belge takibi özelindeki malzeme numarası, isteği açanın mail adresi gibi detay bilgiler de saklanmaktadır.

Request_Action: İșlemsel log bilgilerinin saklanması için kullanılmaktadır. Tarih saat ve kullanıcı bilgileri ile işlem bilgilerini saklar. Örüntü madenciliği için temelde bu tablodaki bilgiler kullanılmıștır.

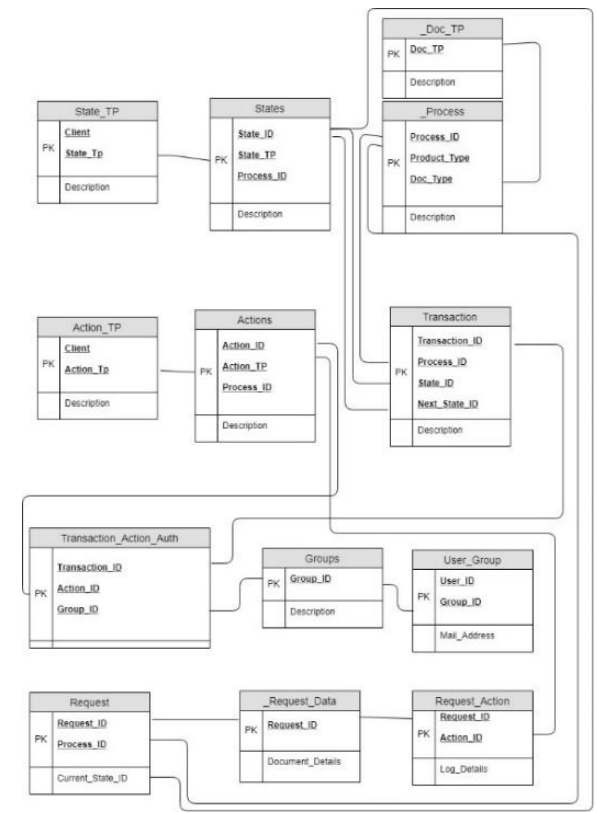

Şekil 2. ER diyagramı 


\section{2. İş akışı örgüleri}

Bir iş akış moturunda, süreçlerin çalışmamızda modellediğimiz ve kullandığımız yapı gereği modelleyemediğimiz temel kontrol akıș kalıpları aşağıda belirtilmiştir. Bu akış kalıpları genel olarak iş akıș motorlarının özelliklerini ifade etmektedir [4].

\subsubsection{Dizi (Sequence)}

Dizi iș akış modeli, herhangi bir koșula bağlı olmaksızın doğrusal olarak bir durumdan diğer duruma geçişi temsil eden en temel kalıptır. Grafiksel gösterim Şekil 3'de belirtilmiştir.

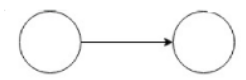

Şekil 3. Dizi akış modeli

\subsubsection{Paralel bölünme (Parallel split AND split)}

Paralel bölünme iș akıș kalıbı bir akıșı böler. $\mathrm{Bu}$ yapıda koșulsuz olarak bir akıșın paralel olarak birden çok duruma bölündüğü durumu temsil eder. Grafiksel gösterim Şekil 4'te verilmiștir.

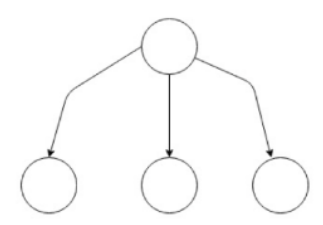

Şekil 4. Paralel bölünme model

\subsubsection{Senkronizasyon (Synchronization AND-}

join)

Senkronizasyon iş akış modeli, birden çok paralel durumun bir tek duruma eșitlenmesini ifade eder. $\mathrm{Bu}$ modelde paralel adımlar tam olarak bir adet durumda birleștirilirler. Grafiksel gösterim Șekil 5'de gösterilmiștir.

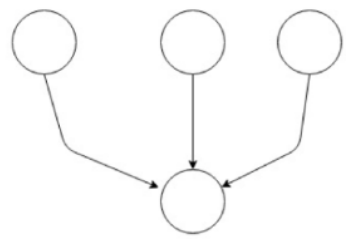

Şekil 5. Senkranizasyon modeli

\subsection{4. Özel seçim (Exclusive choice XOR- split)}

Özel seçim is akıșı kalıbı birden fazla yolu tanımlar. $\mathrm{Bu}$ model içerisinde bir obje birden fazla durum içerisinde bulunabilir. Bu çalıșma kapsamında kullanılan kararlı durum makinesi bu yapıyı desteklemediğinden bu kalıba uygun olarak geliștirilmemiştir. Grafiksel gösterim Şekil 6'da verilmiștir.

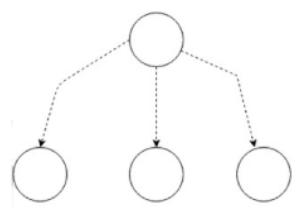

Şekil 6. Özel seçim modeli

\subsubsection{Basit birleștirme (Simple merge XOR-} join)

Basit birleştirme modeli tanımlanmış olası yolları birleştirmek için kullanılır. Tam olarak bir durum için birleştirme tanımlanmıştır. Özel seçim modeline benzer olarak bu yapı da bu çalışma kapsamında geliştirilmemiștir. Grafiksel gösterim Şekil 7'de belirtilmiștir.

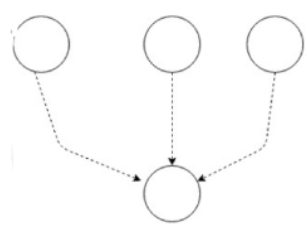

Şekil 7. Basit birleştirme modeli

\subsubsection{Diskriminator (Discriminator)}

$\mathrm{Bu}$ model varsayımlar işler için geliştirilmiştir. Özel seçim ile paralel bölünmenin ortak olarak kullanıldığı bir durumdur. Birden fazla durumun bir duruma bağlandığı ancak objenin bir sonraki duruma geçmesi için gelen tüm durumların tamamlanması gerektiği durumdur. Bir nesne durumu aktivite eder ve diğer durumlardan gelen eylemler de aktivasyonu tamamlar.

$\mathrm{Bu}$ çalışma kapsamında belge takip sistemi özelinde bu model geliștirilmemiș olsa da önerilen yapı bu modelin uygulanması için elverişli şekilde tasarlanmıștır. 


\subsubsection{Keyfi döngüler (Arbitrary cycles)}

İş akış modellerinin genel bir yapısı da içlerinde döngülere izin vermemesidir. İş akış motorlarında bir veya daha fazla etkinliğin tekrarlanması desteklenmez. $\mathrm{Bu}$ çalıșma kapsamında döngülerin engellenmesi için ek bir çalıșma yapılmasa da uygulanan modellerde döngüler gerçekleștirilmemiştir.

\subsubsection{Kesin sonlandirma (Implicit termination)}

İș akışının sonlandırılması genel anlamda objenin geldiği son durumda yeni bir aktiviteye izin verilmediği durum olarak tanımlanmıștır.
Ancak bazı modellerde işlemin doğrudan sonlandırılması da mümkündür. $\mathrm{Bu}$ çalışma kapsamında belge talebi açan kullanıcıların açtıkları talepleri hangi durumda olduğuna bakmaksızın iptal durumuna atayabilecekleri altyapı oluşturulmuştur.

\subsection{9.İptal durumu (Cancel case)}

Bir akış modelinin iptal edilmesi için geliştirilen modeldir. $\mathrm{Bu}$ çalışma kapsamında da iptal tipindeki durum tasarlanmıştır.

Tarif edilen modellerin diğer iș akıșı sistemleri ile karşılaştırılması Tablo 1'de verilmiştir.

Tablo 1. İș akıș motorlarının karșılaștırılması

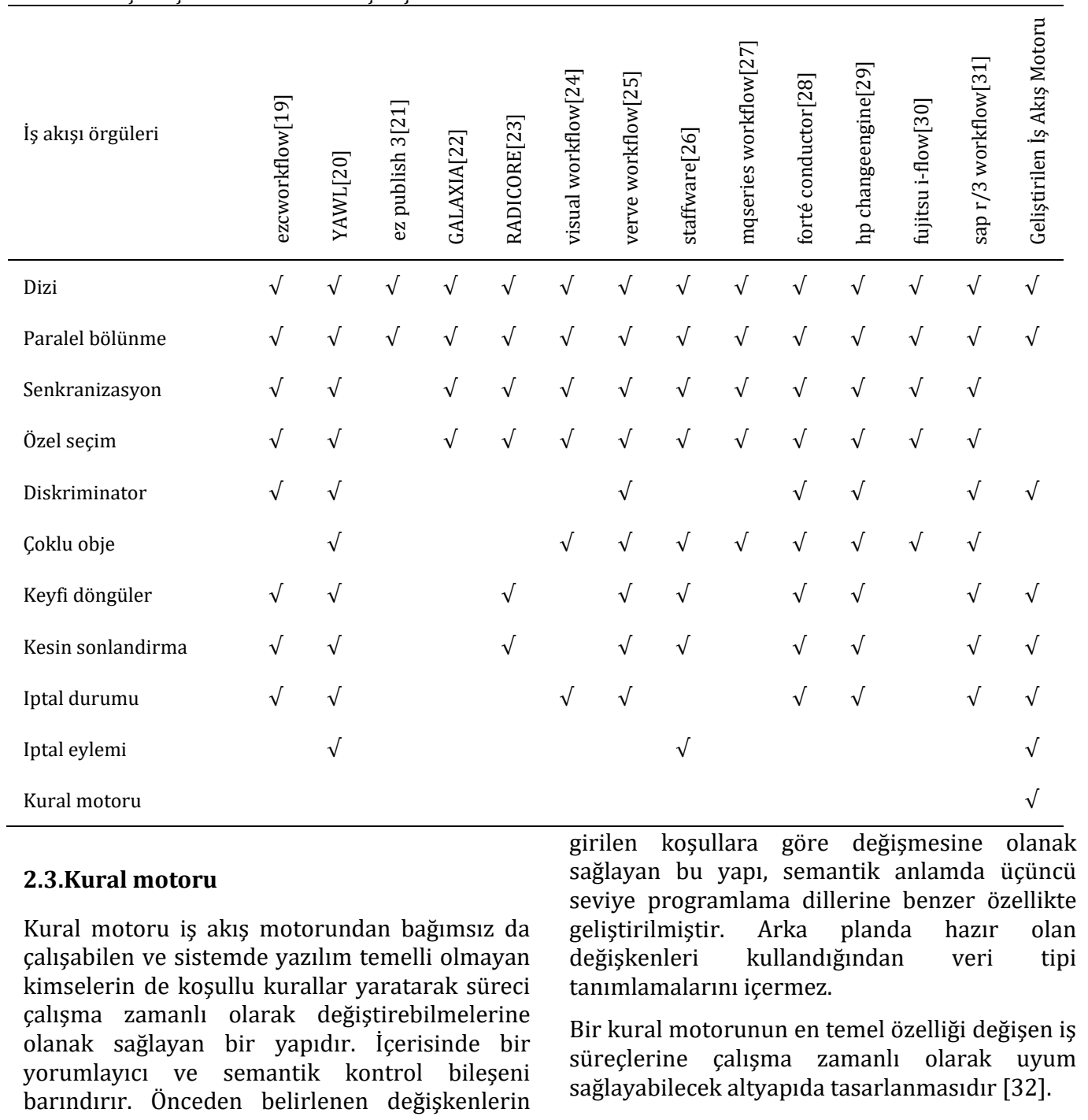


DEU FMD 22(64), 219-231, 2020

Tablo 2. Operant listesi.

\begin{tabular}{|c|c|c|}
\hline Operant & İsim & Açıklama \\
\hline $\mathrm{EQ}=$ & Eşitlik & Eğer operant1 ve operant2 eşitse doğru olarak sonuçlanır. \\
\hline $\mathrm{NE} !=<>$ & Eşitsizlik & Eğer operant 1 ve operant 2 farklı ise doğru olarak sonuçlanır. \\
\hline GT $>$ & Büyüktür & Eğer operant1 operant2'den büyükse doğru olarak sonuçlanır. \\
\hline GE & Büyük ya da eşittir & Eğer operant1 operant2'den büyük ya da eşitse doğru olarak sonuçlanır. \\
\hline $\mathrm{LT}<$ & Küçüktür & Eğer operant1 operant2'den küçükse doğru olarak sonuçlanır. \\
\hline LE & Küçük ya da eşittir & Eğer operant 1 operant2'den küçük ya da eşitse doğru olarak sonuçlanır. \\
\hline $\mathrm{CO}$ & İçerir & $\begin{array}{l}\text { Eğer operant1 operant2'deki karakterleri içeriliyorsa doğru olarak } \\
\text { sonuçlanır. }\end{array}$ \\
\hline $\mathrm{CN}$ & İçermez & CO işleminin tersi durumdur. \\
\hline $\mathrm{CA}$ & İçerir (En az 1) & $\begin{array}{l}\text { Eğer operant } 2 \text { operant1'den en az } 1 \text { karakter içeriyorsa doğru olarak } \\
\text { sonuçlanır. }\end{array}$ \\
\hline NA & İçermez (En az 1) & CA ișleminin tersi durumdur. \\
\hline CS & Karakter içerir & Eğer operant 2 içeriği operant1 içerisinde ise doğru olarak sonuçlanır. \\
\hline NS & Karakter içermez & CS işleminin tersi durumdur. \\
\hline $\mathrm{CP}$ & Örüntü içerir & Eğer örüntü karakter dizisinde varsa doğru olarak sonuçlanır. \\
\hline $\mathrm{CN}$ & Örüntü içermez & $\mathrm{CP}$ ișleminin tersidir. \\
\hline AND & Ve & Eğer iki operatör doğruysa doğru olarak sonuçlanır. \\
\hline OR & Ya da & Eğer herhangi bir operatör doğru ise doğru olarak sonuçlanır. \\
\hline // & Yorum satırı & Yorun satırı başlangıcı için kullanılır. \\
\hline / & Kaçış karakteri & Özel operantlar için karakter kaçış karakteri olarak kullanılır. \\
\hline ( & Sol parantez & Bir koşul ya da atama ifadesi başlatır. \\
\hline ) & Sağ parantez & Bir koşul ya da atama ifadesi bitirir. \\
\hline ; & Noktalı virgül & Satır sonu karakteridir. \\
\hline IF, ELSEIF & Koşul başlangıçı & Koşul başlatma ön ekidir. \\
\hline \multirow[t]{2}{*}{ ELSE } & Son koşul başlangıcı & Son koşul ifadesini başlatır. \\
\hline & Boşluk & Operantlar ve operatör arasındaki ayraç olarak tanımlanmıştır. \\
\hline
\end{tabular}

$\mathrm{Bu}$ çalışmayla geliştirilen kural motoru iş akış Kural motoru içerisinde ifadeler ve ifadelere motoruyla bütünleşik çalışarak ihtiyaç bağlantılı olarak çalışan atamalardan duyulduğunda çalışma zamanlı olarak takip oluşmaktadır. Temel gösterimle bir ifadenin edilen objeye müdahale edebilmesine olanak örnek bir işlemi nasıl çözdüğü de Şekil 8'de sağlamaktadır. gösterilmektedir. 
Bir ifade, bir operant ile birlikte operantın sağında ve solunda operantların bulunduğu semantik bir yapıyı ifade etmektedir.

Bir operant sağında ve solunda bulunan iki operatöre bağlı olarak çeşitli karşılaștırma operasyonları uygulayarak ifadenin doğru veya yanlış sonuçlanması için kullanılmıştır. Bir koşul ifadesinin sonucu yalnızca doğru veya yanlış olarak sonuçlanabilir. İfadenin sonucunun doğru olduğu durumda ifadeyi takip eden atama işlemi gerçekleştirilir.

Operatörler sistem içirişinde önceden tanımlanmış olan değişkenler ya da iç içe çözülmüş olan sorgunun sonucu olan mantıksal doğru ya da yanlıș ifadeleri gösterirler. Operant olarak ise anlamları Tablo 2'de verilen sabitler tanımlanmıștır.

Belge takip sistemi üzerinde kural motorunun örnek bir uygulaması için aşağıdaki formül

ifadesi örnek olarak Şekil 8'de verilmiştir. Burada "current_state", "user_group" ve "doc_type" program içerisinde önceden tanımlanmış değişkenleri ifade eder. Tek tırnak () içerisinde gösterilen değerler ifadeler içerisinde kullanılan sabitlerdir.

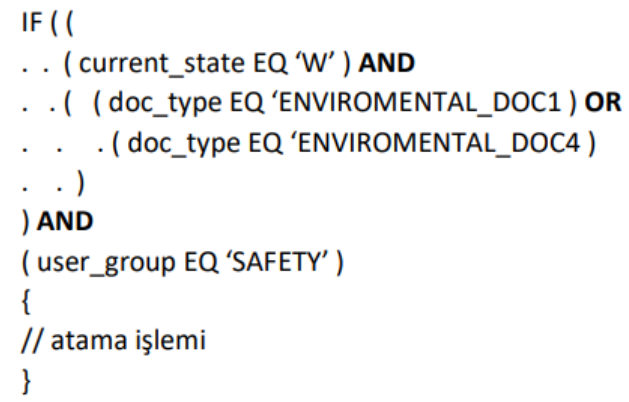

Şekil 8. Basit birleștirme modeli

Sisteme girdi olarak verilen yukarıdaki örnek formül sistem içerisinde sanal bir ağaç yapısına dönüştürülür. Girdideki parantezlerin derinlik seviyelerinin ağacın derinliğini belirlediği bu sistemde yukarıdaki formülün ağaç yapısındaki gösterimi Şekil 9'da gösterilmektedir.

Kuralların işlenişi için kullanılan algoritmanın sözde kodları Algoritma 1'de verilmiștir. "kural_isle" fonksiyonu içerisinde girdi ilk olarak anahtar kelimelere göre koşullara bölünür. Her koşul ilk karakter kümesinin bölümlenmesinin ardından, Algoritma 2'de açlklanan "ifade_isle" fonksiyonuna girdi olarak verilerek işlenir.

"ifade_isle" fonksiyonu koşul ve koşula bağlı atama işlemini girdi olarak alır ve koşul ile ilgili karakter kümesini "ifade_cöz" fonksiyonuna gönderilir. Eğer koşul doğru ise atama ișlemi için atama ile ilgili bölüm "atama_isleme" fonksiyonuna gönderilir.

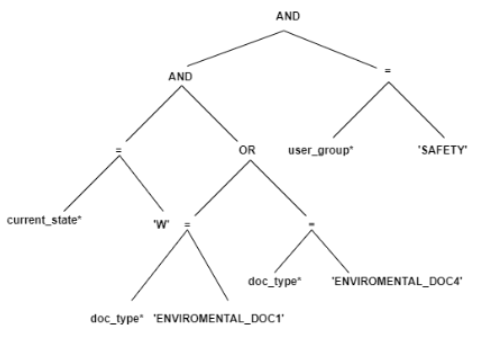

Şekil 9. Örnek ağaç yapısı

Fonksiyon kural_isle (String input)

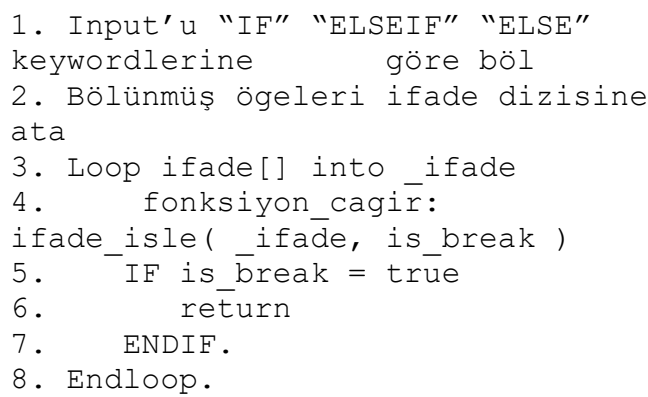

Algoritma 1. Kural işleme

Fonksion ifade_isle ( String ifade, boolean is_break )

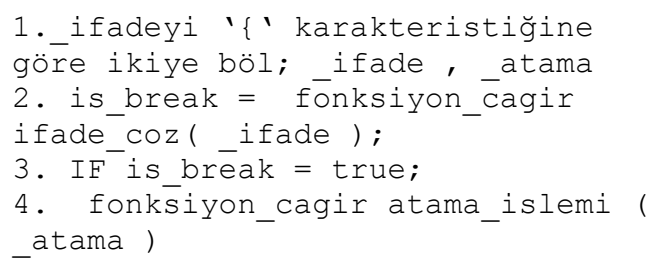

Algoritma 2. İfade işleme

Algoritma 4'de açıklanan "ifade_coz" fonksiyonu girilen koşul ifadesinin doğru ya da yanlış olarak sonuçlandığı fonksiyondur. Özyinelemeli (recursive) formatta çalıșan fonksiyon her bir tekrarda girdi olarak verilen ifadenin çözülmesi ile küçülerek devam eder. Fonksiyondan çıkış koşulu 1. ve 3. satırlar arasında gösterildiği gibi girdinin doğru ya da yanlış olarak belirlenebildiği durumda tetiklenir. 
DEU FMD 22(64), 219-231, 2020

Fonksiyon kendi içerisinde iç içe girmiș koșul ifadelerinden en iç seviyedeki parantezleri belirleyerek ișleme bașlar. 5. ve 14. satırlar arasında koşul ifadeleri atamik ifadeleri bulmak için tasarlanmıştır. Ağaç yapısının yaprak bölümlerinde en iç seviyedeki koşul ifadelerinin operantları yerleștirilir.

Açık parantezden sonra gelen karakter dizisinde bir sonraki parantezin açık parantez olması durumunda atomik olarak en derin ifadenin bulunduğunu gösterir. Döngü içerisinde girdi ifadesinin karakterleri dolaşılarak satır 20 ve 23 arasında atomik ifadeler bulunur ve ilgili indeksler saklanır. Tek bir döngü içerisinde tüm atomik ifadelerin indeksleri belirlendiğinden, bu döngü içerisinde bulunan indeksler arasındaki karakter dizisi Algoritma 3'de verilen "ifade_dogrula" fonksiyonuna gönderilir. Bu fonksiyon Tablo 2'de verilen operatörler ile ifadeyi analiz ederek doğru ya da yanlıș olarak geri döner.

Fonksiyondan dönen doğru ya da yanlış karakteri, temel girdideki belirlenen indeksler arasındaki karakter kümesi ile değiștirilir. Bu adım sonrasında oluşturulan sanal ağaç yapısının en alt seviyesindeki ifadeler çözülmüş olur.

Fonksiyon ifade_dogrula returns string (ifade).

1. İlk ve son karakteri sil

2.Split into operant1 operator operant 2

3.operant1, operant2 değerlerini getir

4.Tablo 2'deki mantığı uygula 5. Return result (doğru ya da yanlış)

Algoritma 3. İfade doğrulama

Fonksiyon ifade_coz return bool (_ifade )

1. IF ifade = true OR ifade =

false;

2.RETURN ifade;

3. ENDIF.

4. LOOP ifade $i++$.

5. IF ifade[i] $\mathrm{EQ}$ '('.

6. check if previous character is

escape symbol

7. IF prev. is escape symbol

8. continue loop;

9. ENDIF.

10. LOOP ifade j++

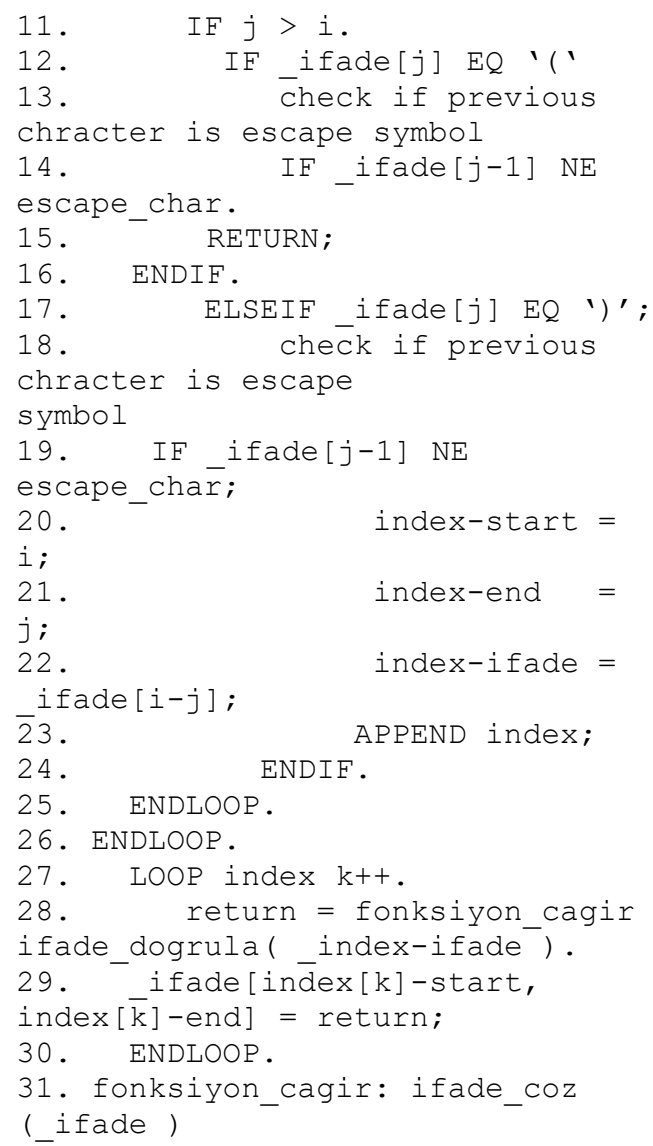

Algoritma 4. İfade çözme

\section{Bulgular}

Çalışma uygulama olarak tamamlandıktan sorna bir firmada gerçek veriler üzerinde denenmiştir. $\mathrm{Bu}$ sayede firmadaki manuel, fiziksel olarak kâğıt veya e-posta yoluyla ișleyen süreç; yazılım içerikli bir sisteme dönmüştür. $\mathrm{Bu}$ süreçte akışların dinamik olarak yaratılabiliyor olduğu görünsede akıș yapısının ve bağımlılıkların sistem performansını etkileyebileceği fark edilmiștir. $\mathrm{Bu}$ nedenle tekrar edilen ișlem maliyetinden kurtulmak adına, belge talep işleminin gerçekleștiği adımda toplanan veriler üzerinden bir siralı örüntü madenciliği çalışması yürütülmüștür.

Bu çalıșmada Apriori yöntemine benzeyen, genelleștirilmiş örüntü madenciliği algoritması (GSP) kullanılmıștır. Genel ișleyișinde GSP algoritması Apriori algoritmasından çok farklı olmasa da; sadece bir öğe için değil de dizi sırası 
için işlem yapılmasını gerçekleştirmesi bakımından birbirinden ayrılmaktadır [33].

$\mathrm{Bu}$ nedenle veri hazırlama süreci farklılık göstermektedir. Ham veriden ișlenmeye hazır olan verinin sağlanması sürecinde; genel ilişkisel veri analizi sürecinde geçersiz verinin kullanımı açısından genel olarak iki farklı yöntem bulunmaktadır. Bu süreçte geçersiz veri analiz sürecine hiç katılmaz, görmezden gelinir ya da geçersiz veri, geçerli verinin ortalaması olarak kullanılır. Ancak sıralı örüntü madenciliğinde, sıralı frekans örüntüleri incelendiğinden bu iki yöntem de tercih edilmemiş ve gereksiz verinin tamamı anlamlı tek tip olacak şekilde varsayılmıştır [34].

$\mathrm{Bu}$ çalışmada veri madenciliği aracı olarak WEKA [35] kullanılmış ve veri özelleştirilmiş üç tablo üzerinden bir programla veriler .txt formatında dıșarıya aktarılmıștır. Kullanılan tabloların yapısı Şekil 10'da verilmiştir.

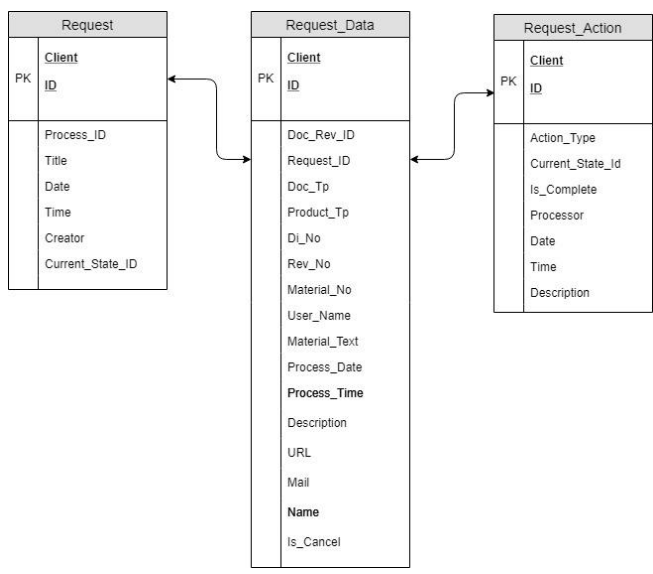

Şekil 10. Veri kümesi oluşturulurken kullanılan tablolar

Veri kümesini oluşturabilmek için canlı sistemden alınan tablolar lokal alana txt formatında indirilmiş ve sonrasında dosya işlemleri yapabilen bir program üzerinde WEKA aracına girdi olarak kullanabilecek bir formata dönüștürülmüştür. Program içerisinde aşağıda detayları verilen tablolardaki verilerden girdi olarak kullanılmıștır.

Request: İş akışı motorunda isteği yapılan nesneye ait genel bilgiyi saklar.

Request_Data: İș akıșı motorunun her bir farklı amaç için gerçekleştiriminde farklılaşan istek tablosudur. Belge takibi için kullanılan formda içerisinde isteği yapılan malzeme için ek alanlar bulundurur.

Requset_Action: İsteği yapılan obje üzerinde bir $t$ anına kadar gerçekleșen aksiyonları saklar. $\mathrm{Bu}$ tablo bir log yapisı olarak da değerlendirilmektedir.

Sıralı örüntülerin arandığı yapılarda uzun metin ifadeleri performansı olumsuz yönde etkilediğinden ilk olarak belge türleri için etiketler oluşturulmuştur. Bu noktada geçerli olmayan, gerçek olmayan bazı veriler olduğu görülmüștür. Sistemin kurulumu ya da ileriki zamanlarda son kullanıcı kaynaklı bazı hatalar sonucu bu gerçek dişı görünen durumların oluştuğu/ortaya çıktı̆̆ değerlendirilmiștir. Ancak alışılagelmiş yöntem olan bu verilerin yok sayılması bu çalıșma için uygun bulunmamıștır. Çünkü silinen bir belge talebi, bir sıralı ilişkiyi bozacağı ve belki de mümkün olan en uzun sıralı örüntünün kaybolmasına sebep olacağı için değerlendirme dışına alınmamıștır. Bu süreçte geçersiz verinin işlenmesi için farklı bir yöntem kullanılmıştır. Geçerli olmayan sıralar için yeni bir etiket kullanılarak tüm veriyi eksiltmeden işlem yapılabilecek bir veri kümesi oluşturulmuştur.

Girdi olarak dosya alan program, çıktı olarak da WEKA aracına girdi olabilecek formatta içerisinde zamanında bulunduğu bir dosya ortaya çıkarmaktaktadır. Veri kümesi sadece belge etiketleri, tarih ve saat içerecek şekilde oluşturulmuştur.

Tarih ve saat birleştirilerek ayrıca sıralanmış ve tekrarsız bir sayı dizisine dönüștürülmüștür. Son durumda veri seti içerisinde yalnızca sırayı gösteren sayllar ve belge isimlerini betimleyen etiketler bulunmaktadır. Örnek bir veri kümesi Şekil 11'de gösterilmiştir.

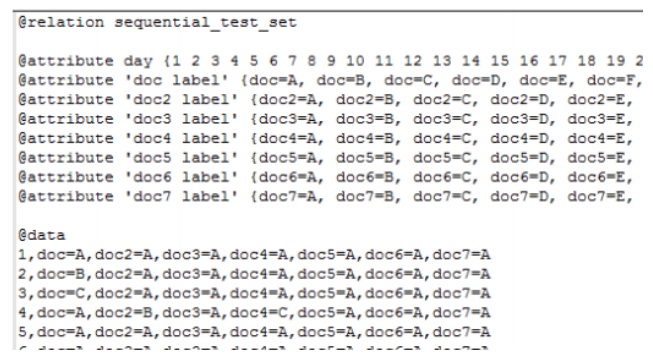

Şekil 11. Örnek bir veri kümesi 
En düşük destek değerinin 0,6 belirlendiği test sonuçlarında iki adet belge etiketi çifti, en düşük destek değerini 0,9 belirlendiği test sonuçlarında da bir adet belge etiketi çifti sınırın üzerinde hesaplanmıștır.

\section{Sonuç}

Bu çalışma kapsamında aktivite tabanlı bir kural motoru geliștirilmiştir. Geliștirilen bu yapı, iș akış motorunun en temel özelliklerinden tekrarlı yapıları sağlayabilmesi için bir kural motoru ile desteklenmiştir.

Fabrikanın manuel olarak yönettiği bu süreç otomatize edildiğinden raporlamaya uygun hale getirilmiş ve belge talepleri arasında sistemde bir kuyruk yapısının oluşması sağlanmıștır. Akışın sistem üzerinden yürümesi belgelerin yalnızca ilgili kişilere ulaşmasını sağladığından sisteme bir güvenlik önlemi katkısı da sunmuştur.

Ayrıca projenin canlı sisteme geçişinden sonra altı ay veri girişi takip edilmiş ve işlemsel log dosyaları sıralı örüntü madenciliği uygulamasının giriş dosyası olacak şekilde formatlanmıştır. Uygulama sonuçları ilgili iş birimleri ile paylaşılmış ve sistemin daha hızlı işlemesi için bu araştırma sonuçları kullanılmıştır.

\section{Kaynakça}

[1] Chung S., Synder C. 1999. ERP initiation -a historical perspective, Proceedings of AMCIS'99, s. 213-215.

[2] Ouyang C., Adams M., Wynn M., Ter A. 2010. Workflow Management, Handbook on Business Process Management 1: Introduction, Methods, and Information Systems, s. 387-418 DOI: 10.1007/9783-642-00416-2.

[3] Marek R, Amit S. 1995. Specification and execution of transactional workflows. In Modern database systems, ACM Press/Addison-Wesley Publishing Co., New York, NY, USA, s. 592-620.

[4] Bergmann S. 2007. Design and implementation of a workflow engine", Diploma thesis of, Rhenish Friedrich Wilhelm University, Siegburg 92s.

[5] McCoy, D. W. and Sinur J., Achieving Agility: The Agile Power of Business Rules, Gartner, Special report on Driving Enterprise Agility, 20 April 2006.

[6] De Leusse P. Kwolek B. Zielinski K 2012. A common interface for multi-rule-engine distributed systems, Distributed System Research Group, AGH University of Science and Technology Krakow, Poland

[7] Diimitrios G., Mark H., Amit S. 1995. A n overview of workflow management: from process modeling to workflow automation infrastructure, Distributed and Parallel Databases Cilt 3, s 119-153.
[8] Wil van der Aalst, Kees van Hee 2000. "Workflow management models, methods and systems", Eindhoven, Hollanda.

[9] Bouafia, K., Molnár B. 2018. Dynamic business process: comparative models and workflow patterns, The 11th conference of phd students in computer science volume of short papers CS2. 194, June 2018 Szeged, Magyarország.

[10] Krasimira P. S. Todor A. S. 1999. Evolution of the workflow management systems, Information system, Cilt 28 s 27-60.

[11] De Lay, E, Jacobs D. 2011. Rules-based analysis with JBoss Drools: adding intelligence to automation, Proceedings of ICALEPCS 2011, s. 790-793.

[12] Rakesh A., Dimitrios G., Frank L. 1998. Mining Process Models from Workflow Logs In Proceedings of the 6th International Conference on Extending Database Technology: Advances in Database Technology (EDBT '98), Hans-Jörg Schek, Fèlix Saltor, Isidro Ramos, and Gustavo Alonso (Eds.). Springer-Verlag, Berlin, Heidelberg, s 469-483.

[13] Aalst W.M.P., F. van Dongen B., Herbst J. Măruşter L., Schimm G., Weijters A. 2003. Workflow mining: a survey of issues and approaches. Data \& Knowledge Engineering. Cilt 47(2) s 237-267 DOI: 10.1016/S0169-023X(03)00066-1.

[14] Singh G. N., Sandeep A. 2011. A process model for workflow mining, International Journal of Information Technology and Knowledge Management, Cilt. 4(2) s. 719-722.

[15] Allen, R. 2001 Workflow: An Introduction" in: WfMC Workflow Handbook 2001, L. Fischer (ed.), Future Strategies Inc, Florida US, s15-38.

[16] Lucas, S. M., Reynolds, T. J. 2005. Learning deterministic finite automata with a smart state labeling evolutionary algorithm. IEEE Transactions on Pattern Analysis \& Machine Intelligence, Cilt 7, s. 1063-1074. DOI: 10.1109/TPAMI.2005.143

[17] Xiangru XU, Yiguang H. 2012 .Matrix expression and reachability analysis of finite automata. J Control Theory Appl, 10(2) s 210-215.

[18] Molnár, B., Máriás Z. 2015. Design and Implementation of a Workflow Oriented ERP System, International Conference on e-Business, s. 160-167.

[19] ZETA Workflow http://zetacomponents.org /news.html (Erișim Tarihi 10.06.2019)

[20] Van Der Aalst, W. M., Ter Hofstede, A. H. 2005. YAWL: yet another workflow language. Information systems, Cilt. $30(4)$, s. 245-275. DOI: 10.1016/j.is.2004.02.002

[21] Pirt, B. 2004. Learning eZ publish 3: Building Content Management Solutions. Packt Publishing Ltd.

[22] Galaxia Workflow https://galaxyproject.org/ learn/advanced-workflow/ (Erişim Tarihi 10.06.2019)

[23] Radicore Workflow. https://www.radicore.org/ viewarticle.php?article_id=3 (Erișim Tarihi 10.06.2019)

[24] Visual Workflow https://www.adobe.com/tr/ marketing/experience-manager-forms/visualworkflow-editor.html (Erişim Tarihi 10.06.2019) 
[25] Verve Worklow http://www.lateralsystems. com.au/verve-cms-1.html (Erişim Tarihi 10.06.2019)

[26] Staffware http://www.workflowpatterns.com/ vendors/staffware.php (Erișim Tarihi 10.06.2019)

[27] MQSeries Workflow https://www.ibm.com/ support/knowledgecenter/en/SSFKSJ_7.1.0/com.ib m.mq.doc/fg15350_htm (Erișim Tarihi 10.06.2019)

[28] Ran, S., Brebner, P., Gorton, I. 2001. The rigorous evaluation of Enterprise Java Bean technology. In Proceedings 15th International Conference on $\begin{array}{lll}\text { Information Networking. } & \text { s. } & 93-100\end{array}$ DOI: 10.1109/ICOIN.2001.905336

[29] HP ChangeEngine http://www.hp.com/hpinfo /newsroom/press_kits/2009/HPSoftwareUniverse Hamburg09/HPOODataSheet.pdf (Erişim Tarihi 10.06.2019)

[30] Fujitsu i-Flow http://www.iflowbpm.com/ (Erişim Tarihi 10.06.2019)

[31] SAP R/3 Workflow https://wiki.scn.sap.com / wiki/pages/viewpage.action?pageld $=473964457$ (Erişim Tarihi 10.06.2019)

[32] Swamynathan, S., Geetha, T.V. 2014 Active rule engine for dynamic business rules https://www.researchgate.net/publication/249903 201_ACTIVE_RULE_ENGINE_FOR_DYNAMIC_BUSIN ESS_RULES (Erişim Tarihi 10.06.2019)

[33] Desai, N., Ganatra, A. 2014. Draw Attention to Potential Customer with the Help of Subjective Measures in Sequential Pattern Mining (SPM) Approach, Conference: Proc. of Int. Conf. on Recent Trends in Information, Telecommunication and Computing, ITC

[34] Zhang S., Zhang C., Yang Q. 2003 Data preparation for data mining. Applied Artificial Intelligence,Cilt 17(5-6) s. 375-381.

[35] WEKA, Open source machine learning tool. https://www.cs.waikato.ac.nz/ml/weka/ (Erişim Tarihi 10.06.2019) 